\title{
ARTIGOS
}

\section{ALGUNS MOMENTOS DO DEBATE SOBRE AS TEORIAS DO 'NAOO-SI'E DAS 'DUAS VERDADES' NA HISTÓRIA DA FILOSOFIA BUDDHISTA}

Giuseppe Ferraro* giuseppeferraro2003@yahoo.com.br

RESUMO $O$ artigo reconstrói alguns momentos salientes do desenvolvimento das doutrinas do 'não-si'e das 'duas verdades' na história da filosofia buddhista, desde as formulações originárias do buddhismo de base, às conclusões alcançadas por Nāgārjuna, o fundador da escola mahāyāna do Madhyamaka. Ao longo dessa sintética reconstrução, algumas passagens das Mūlamadhyamikakārikās de Nāgārjuna, cruciais para entender a sua (controversa) concepção epistemológica, mostrar-se-ão semelhantes, no tocante à estruturação e ao desenvolvimento do discurso, à primeira parte das Milinda Pañha, um diálogo para-canônico que escolhe uma abordagem apofática para tratar o tema da 'verdade última'. Tal paralelismo formal entre as passagens dos dois textos sugere a possibilidade de uma correspondência 'substancial' entre a concepção nagarjuniana e aquela das Milinda Pañha no que se refere ao 'ultimamente verdadeiro'.

Palavras-chave Não-si, verdade convencional, verdade última, vacuidade, Nāgārjuna, Milinda Pañha.

ABSTRACT The paper reconstructs some prominent stages of the development of the "non-self" and the "two truths" doctrines in Buddhist philosophy, from original formulations of mainstream buddhism, to the conclusions reached by Nāgārjuna, the founder of mahāyāna school of

* Doutorando em Filosofia pela UFMG. Artigo recebido em 17/03/2010 e aprovado em 20/06/2010.

KRITERION, Belo Horizonte, nº 123, Jun./2011, p. 7-29. 
Madhyamaka. During this concise reconstructions, some passages of Nāgārjuna's Mūlamadhyamikakārikās, which are crucial to clarify his (controversial) epistemological conception, will prove themselves similar, regarding the structuring and the development of the discourse, to the first part of Milinda Pañha, a para-canonical dialogue which takes an apofatic approach to deal with the topic of the 'ultimate truth'. This formal parallelism between the passages of the two texts suggests the possibility of a 'substantial' correspondence between the nagarjunian conception and that of Milinda Pañha with regard to the 'ultimately true'.

Keywords Non-self, conventional truth, ultimate truth, emptiness, Nāgārjuna, Milinda Pañha.

\section{Introdução}

A metafísica da escola buddhista do Madhyamaka ${ }^{1}$ é centrada na doutrina da 'vacuidade de todos os entes' (sarva-dharma-śūnyatā); tal concepção constitui o desenvolvimento mais avançado e radical de um longo percurso filosófico, cujas raízes afundam em um ensinamento original - a teoria do 'não-si' (anātma-vāda) - do Buddha ${ }^{2}$ histórico e que se desenrola ampla e articuladamente em todas as escolas buddhistas ${ }^{3}$.

1 A escola do Madhyamaka ('Caminho do Meio') - uma das tradições do buddhismo do Mahāyāna ('Grande Veículo') - foi fundada por (ou, mais corretamente, se desenvolve a partir da obra de) Nāgārjuna, provavelmente durante o século II d.C.

2 A versão 'aportuguesada' - 'Buda' e 'darma' - das palavras sânscritas Buddha e dharma, não respeita a fonética original das mesmas. Ao longo desse artigo, seguindo a práxis utilizada pelos estudos científicos sobre o buddhismo nas principais línguas européias, considerou-se oportuno seguir a transliteração mais fiel às letras e às sonoridades presentes nos originais sânscritos. Consequentemente, ao invés de 'budismo', 'budista', 'dármico' e eventuais outros termos derivantes de 'Buda' e 'darma', preferimos os inusitados (embora, de qualquer forma, já atestadas em algumas publicações em língua portuguesa) 'buddhismo', 'buddhista', 'dhármico', etc.

Conforme o mesmo princípio - o de seguir o 'padrão internacional' dos estudos buddhistas -, contra o uso prevalente (não, porém, exclusivo) da língua portuguesa de não se colocar o artigo antes da palavra 'Buddha' (que é um adjetivo e não um nome próprio), achamos preferível manter o artigo 'o' diante do nome 'Buddha'. A palavra buddha, isto é, 'desperto', tornou-se o epíteto mais comum para designar o 'desperto' Siddhārta, do clã dos Gotamas (também conhecido como Śākyamuni, 'o sábio da tribo dos Śākya', nascido em Lumbinī, no norte da Índia, no ano 563 a.C - segundo uma datação mais tradicional; até 100 anos depois, segundo estudos mais recentes - e morto 80 anos depois em Kusinārā, ainda na Índia do norte), a dizer, o 'Buddha histórico'. Outros buddha, míticos ou reais, apareceram - até antes da própria fundação do buddhismo como sistema filosófico-religioso - na história do mundo, e outros aparecerão, afirma a tradição buddhista, mas, efetivamente, com 'o Buddha' entende-se unicamente o Buddha histórico Śākyamuni.

3 A história da filosofia buddhista pode ser basicamente articulada em três fases (cf. P. Siderits, 2007, p.14): 1) o conjunto das ideias e dos ensinamentos originais do Buddha histórico, contidos nos nikāya ('compilações') - das quais é composto o 'cânone' buddhista - que relatam, mais ou menos fielmente, 
Paralela ao desenvolvimento da metafísica buddhista, e a ela indissoluvelmente entrelaçada, desdobra-se uma epistemologia, que possui a finalidade principal de justificar e de defender as conclusões progressivamente alcançadas pela reflexão ontológica. Uma epistemologia, ela também, centrada sobre uma ideia fundamental - a teoria das 'duas verdades' - dinamicamente capaz de se adaptar às várias concepções sobre o ser propostas pelas diferentes escolas.

A doutrina mādhyamika ${ }^{4}$ da 'vacuidade de todos os entes', portanto, é acompanhada e corroborada, por sua vez, por uma particular declinação da teoria epistemológica das 'duas verdades'.

O ponto de partida do presente artigo é o fato de que tanto a metafísica, quanto a epistemologia do Madhyamaka não foram entendidas, pelos antigos comentadores, pelos adversários de Nāgārjuna e por seus exegetas contemporâneos, em modo unânime. Pelo contrário, o seu pensamento foi interpretado de forma vária e, frequentemente, discrepante.

Quantas e quais exatamente sejam tais possibilidades interpretativas não é o ponto em questão nessas páginas; tampouco, tentaremos aqui apresentar argumentos definitivos a favor de uma ou de outra entre essas diferentes hipóteses hermenêuticas.

Ao invés disso, os propósitos deste artigo são: 1) na primeira parte, apresentar sinteticamente (com a indicação, nas notas de pé de página, de possíveis direções de aprofundamento) os termos essenciais do debate filosófico que, ao longo da história do pensamento buddhista, se desenvolveu sobre as temáticas do 'não-si' e das 'duas verdades'; 2) na segunda parte, analisar o incipit de um importante texto paracanônico - o Milinda Pañha ("Perguntas de Milinda", daqui em diante MP) -, cuja estruturação do discurso se assemelha em muito à maneira com a qual Nāgārjuna, no capítulo 24 (ou

os seus discursos; 2) a sistematização e a re-elaboração desses ensinamentos originários do Buddha, efetuadas pelas (tradicionalmente) 18 escolas do Abhidharma ('Ensinamento ulterior [ou superior]'); 3) a crítica das teorias (metafísicas e epistemológicas) das escolas abhidharmika e a busca do significado mais profundo do ensinamento do Buddha - efetuadas pelas escolas do movimento Mahāyāna.

A segunda dessas duas fases equivale ao que, no âmbito da tradição mahāyāna - e, consequentemente, por uma parte da literatura secundária contemporânea -, foi definido, pejorativamente, Hīnayāna, ('Pequeno Veículo'). Mais recentemente, a tendência é de se referir às fases primitivas do buddhismo com expressões não depreciativas: por exemplo, E. Cheetman (1994), seguido pelo importante estudo de P. Williams (2002), designa o buddhismo pré-mahāyāna como 'buddismo de base' ('mainstream buddhism'). Vale a pena ainda lembrar que a fase abhidharmika da história da filosofia buddhista precede o Mahāyāna, mas, por alguns séculos (e, com certeza, na época de Nāgārjuna), também o acompanha. O Mahāyāna surge enquanto a maioria das escolas abhidharmika estão ainda em pleno vigor. A classificação dessas escolas como pré-mahāyāna deve ser entendida, portanto, mais em sentido lógico do que cronológico.

4 'Madhyamaka' é o nome da escola, enquanto mādhyamika é o adjetivo que designa o que pertence à mesma escola. 
seja, na parte da sua obra provavelmente mais importante para investigar a sua epistemologia) das Mūlamadhyamakakārikās ("Versos fundamentais do Caminho do Meio", daqui em diante MMK), aborda a questão das 'duas verdades'.

Dessa forma, em primeiro lugar, os discursos de Nāgārjuna serão colocados dentro das coordenadas histórico-filosóficas que mais propriamente the pertencem. Em segundo, dando ênfase às semelhanças extrínsecas entre MP e MMK.24, concluir-se-á que, por trás do paralelismo formal, possa existir um paralelismo 'substancial' e que, portanto, as MP sejam um texto fundamental a ser levado em consideração por qualquer abordagem interpretativa da filosofia de Nāgārjuna que pretenda ser escrupulosa.

O formalismo e a fria analiticidade com os quais Nāgārjuna conduz o seu discurso nas MMK acabaram levando alguns de seus exegetas contemporâneos a tentativas de interpretá-lo - na base de critérios hermenêuticos puramente lógico-analíticos - fora do contexto filosófico em que ele viveu e operou ${ }^{5}$. Parece, porém, metodologicamente imprescindível reconduzir constantemente Nāgārjuna ao meio filosófico com o qual ele dialoga e, em particular, àqueles textos cuja autoridade ele devia mais respeitar ${ }^{6}$.

\section{Elementos essenciais da Metafísica e da Epistemologia Buddhistas}

\subsection{Formulação original da doutrina do não-si}

Entre as numerosas doutrinas buddhistas filosoficamente relevantes, aquela sobre a 'não-existência do si' (anātma-vāda) é, provavelmente, a mais original e característica. Transmitida pelo Buddha histórico desde o começo da

5 A falta de uma forte contextualização da obra de Nāgārjuna é, por exemplo, um defeito perceptível em dois recentes trabalhos que visam demonstrar o radical niilismo da filosofia nagarjuniana: T. Wood (1994), D. Burton (1999). Também algumas abordagens 'analíticas' à filosofia de Nāgārjuna, parecem carecer de uma correta perspectiva histórico-filosófica: p.e., R. H. Robinson (1972) ou R. Hayes (1994).

6 Em um recente trabalho, J. Walser (2005) argumenta convincentemente que o movimento Mahāyāna, desenvolvendo-se, inicialmente, dentro de um meio monástico 'Hinayāna', para assegurar a conservação e a reprodução dos seus textos, precisava demonstrar que a doutrina neles conteúda pudesse ser percebida, naquele mesmo meio, como 'palavra do Buddha' (buddhavacana).

D. Seyfort Ruegg (1995) - que utiliza uma terminologia própria da antropologia de K. L. Pike - afirma que a abordagem às fontes primárias da filosofia buddhista deveria ser, pelo menos em primeiro lugar, emic mais do que etic; ou seja, os autores e as temáticas estudadas deveriam ser relacionados, primeiramente, às categorias culturais e aos horizontes intelectuais aos quais eles pertencem; apenas em um segundo momento - eventualmente e na base dos resultados alcançados na fase emic - pode ocorrer a abordagem etic, que relacione as ideias analisadas a terminologias e a categorias filosóficas mais gerais e as coloque em uma dimensão comparativa com os termos do debate filosófico moderno 'ocidental'. 
sua predicação ${ }^{7}$, essa foi aprofundada em discursos sucessivos ${ }^{8}$ e, em seguida, desenvolvida por vários modos, re-elaborada e aprimorada pelas diferentes escolas buddhistas tardo-antigas e medievais.

Em extrema síntese, o anātma-vāda baseia-se na tese de que o 'si' individual - a alma, o ego, a subjetividade singular - é uma sensação ilusória, que se engendra em uma dimensão cognitiva baixa e ordinária, e à qual não corresponde nada de objetivo e de ultimamente real.

O Buddha, nos seus discursos sobre o 'não-si', reduz a inteira experiência psícofísica individual ao fluxo de cinco skandha (pāli ${ }^{9} k$ handha, 'aglomerações' ou 'agregados'): forma física (rūpa), sensação (vedanā), ideação (samñjā, pāli sañña), volições (samskārāh, pāli samkhārā) e consciência (vijñāna, pāli viñ̃āna). Nenhum desses agregados equivale a um si permanente, nem contém algo de parecido com um ego ou com um substrato espiritual ${ }^{10}$. Pelo contrário, todos eles são destituídos de substancialidade, caracterizando-se como fluxos interconexos de instantes psíquicos e materiais.

A concepção anātma foi interpretada extensivamente por todas as escolas buddhistas, incluindo nela a ausência de qualquer 'forma' (em sentido aristotélico) ou essência individual dentro das coisas. Não somente, portanto, os sujeitos são desprovidos de um si, mas também os objetos não têm nenhuma identidade própria (svabhāva), que os individue e os separe dos outros objetos. As divisões no mundo material são somente conceituais e ilusórias: a elas não corresponde nada de real. Não há um discurso específico do Buddha que sustente essa ideia da ausência do 'si' no mundo das coisas, mas essa conclusão pode ser deduzida por várias passagens da literatura canônica ${ }^{11}$.

7 O Anattalakkhana Sutta ('Discurso sobre as marcas do não-si'), tradicionalmente considerado o segundo discurso pronunciado pelo Buddha depois da iluminação, é o locus clássico, na literatura canônica, em que encontramos a doutrina do 'não-si'.

8 Cf., p.e., Phena Sutta ('Discurso da espuma'), Saṃyutta Nikāya ('Coletânea [dos discursos] reunidos'), 22.95

9 O pāli é a língua na qual os discursos originais do Buddha são registrados no canône da escola Theravāda. É um idioma hindu-ario que se apresenta como um vernáculo, ou seja, uma língua falada (contra a artificialidade e o tecnicismo do sânscrito) na Índia oriental. No entanto, R. Torella observa (2008, p. 181) que, junto ao ardhamāgadhī (a língua do janismo antigo), o pāli é uma língua com um alto nível de sofisticação, bem parecido ao sânscrito que adversa.

10 O Phena Sutta representa cada um dos cinco agregados com a imagem de um objeto que não tem 'cerne' ou 'miolo'. P.e., o agregado 'volições' é comparado ao tronco de uma arvore de bananeira, composto de uma série de camadas que, uma vez descascadas, relevam completa ausência de âmago.

11 Cf., p.e, Culasuññata Sutta ('Discurso breve sobre a vacuidade'), Majjhima Nikāya ('Coletânea [dos discursos] de médio tamanho'), 121; ou Suñña Sutta ('Discurso sobre o vazio'), Saṃyutta Nikāya, 35.85. No geral, como observado por N. Ross Reat (em K. Potter [1996-99], vol.VII, p. 40), a falta de substancialidade da realidade física, mais frequentemente, é indicada pela palavra anitya (pāli anicca. 'impermanência') que, junto com anātman (pāli anatta) e duhkha ('sofrimento', pāli dukkha. "Often rendered in English as 'suffering' [...] 'Unsatisfactoriness' or 'frustration', however, are more adequate", N. Ross Reat, cit., p.34) é uma das 'três marcas' (Trilakșana, pāli, Tilakkhana) da realidade. 
A ideia de que a atividade psicofisíca humana seja produzida, contida e organizada por um sujeito individual, dotado de características próprias e irredutíveis, acrescida da ideia de que os objetos sejam algo de substancial e separado, é considerada pelo Buddha o erro fundamental, a partir do qual se originam a aflição e o sofrimento que definem em primeiro lugar a existência humana. As diferentes 'contaminações' que, literalmente, envenenam ${ }^{12}$ a nossa vida - principalmente o apego (trṣnāa , pāli tanhā) e a aversão (dveșa, pāli dosa) - surgem e se reproduzem, justamente, a partir da convicção de que exista um 'ego', um 'fruidor', um sujeito contraposto a outros sujeitos e ao mundo dos objetos. Pelo contrário, a remoção do ofuscamento mental (moha) ou da nesciência (avidyā, pāli avijjā) que nos conduz a acreditar em um centro ou um substrato da nossa experiência existencial tem o poder de purificar a existência das contaminações, livrando-a do sofrimento ${ }^{13}$.

\subsection{Aparente contraste entre ontologia e ética buddhistas e sua solução} epistemológica

Sob o ponto de vista daquela que podemos denominar 'ortodoxia filosófica' buddhista, a doutrina do 'não-si' impõe-se como um ponto firme e indiscutível, frequentemente utilizado como referência 'normativa' para julgar a legitimidade de uma ou de outra teoria (ontológica, em primeiro lugar), ou até de uma inteira escola ou movimento ${ }^{14}$. No entanto, a circunstância de que a sua plena adoção por parte de todos os buddhistas seja - pelo menos programaticamente (os eventuais desvios dela são sempre 'involuntários') - inquestionável, não significa que a mesma adoção seja sempre simples e isenta de dificuldades.

12 Kleśa, que costuma ser traduzido com 'contaminação' significa, também, 'veneno'.

13 A moldura geral em que qualquer teoria ou preceito buddhista devem ser colocados é a concepção das Quatro Nobres Verdades (justamente apresentada pelo Buddha no seu primeiro discurso, o Dhammacakkappavattana Sutta, "Discurso sobre a colocação da roda do Dharma em movimento"), ou seja, quatro afirmações axiomáticas que conferem ao buddhismo o status de sistema filosófico: 1) o sofrimento é a marca fundamental da existência; 2) o sofrimento tem causas, a mais básica das quais é a nesciência; 3) existe a possibilidade de pôr fim ao sofrimento; 4) existem oito comportamentos que permitem a extinção do sofrimento: entre eles, o primeiro é a 'reta visão' (samyagdrșți, pāli, sammāditthi) das coisas, ou seja, a dissolução da nesciência.

14 As escolas Theravāda e Sarvāstivāda, por exemplo, criticam as escolas Vātsīputrīya e Sāmmatīya (das quais, porém, conhece-se muito pouco) por elas sustentarem a visão pudgalavāda, ou seja, uma psicologia 'personalista', a qual parece contradizer a correta compreensão da teoria do 'não-si'.

Por sua vez, a escola Sarvāstivāda defende uma concepção da duração temporal dos elementos, a qual é julgada como ‘substancialista', logo, herética, pela escola Sautrāntika.

Ou enfim, pode-se dizer que o inteiro movimento Mahāyāna se opõe à tradição das escolas abhidharmika, do ponto de vista teórico (sendo que o Mahāyāna exerce também fundamentais críticas à ética daquelas escolas), devido à interpretação que elas dão da doutrina do 'não-si'. 
Além do problema fundamental de penetrar no sentido profundo (isto é, o sentido 'empírico', além do meramente conceitual) da doutrina do 'não-si' - tarefa à qual o adepto buddhista deve dedicar os seus esforços na prática meditativa, que possui a finalidade de 'vivenciar' a não existência do si individual -, a sua principal dificuldade reside no fato de que ela parece (pelo menos de um ponto de vista lógico) dificilmente conciliável com outras doutrinas ensinadas pelo Buddha, isto é, com ensinamentos que gozam do mesmo caráter inquestionável da teoria do anātma.

Poder-se-ia perguntar, por exemplo, não existindo a individualidade dos seres humanos e das coisas, para o benefício de quem seriam os próprios ensinamentos do Buddha? Quem é que sofre, quem se deveria livrar do sofrimento? E, sob o ponto de vista ético, quem poderia cumprir ações boas ou más? $\mathrm{Ou}$, enfim, quem descontaria, na existência futura, os resultados 'cármicos' amadurecidos ao fim da vida presente?

Evidentemente, são numerosos os discursos do Buddha que, apesar de nunca afirmado explicitamente, pressupõem a existência de um si, de uma individualidade ou, pelo menos, de uma continuidade pessoal: grande parte da ética e da soteriologia ensinadas pelo Buddha parece fazer sentido somente num contexto em que as pessoas existem como indivíduos.

A maneira pela qual os pensadores buddhistas tentaram resolver o dilema da aparente contradição entre discursos anātma (centrados sobre o 'não-si') e âtma (centrados sobre o 'si pessoal') do Buddha foi aquela de distinguir, dentro do seu ensinamento, dois níveis epistemológicos: um nível 'convencional' (à altura do qual se colocam todos os ensinamentos do Mestre os quais pressupõem existência de individualidade separada) e um nível 'último' (ao qual pertence a doutrina do não-si) ${ }^{15}$.

A necessidade desses dois níveis de verdade surgiu pelas exigências 'pedagógicas' que o Buddha teve que enfrentar: a sua audiência não era composta por ouvintes do mesmo nível de desenvolvimento intelectual e

15 A distinção paramārtha / saṃvịti (pāli, paramattha / sammuti), ou seja, 'último / convencional' é posterior àquela nitärtha / neyārtha (pāli nïthattha / neyyattha), a saber, '[discursos] de significado definitivo / [discursos] provisórios'. Uma distinção que encontramos, p.e., em Ariguttara Nikāya ('Coletânea [dos discursos] em progressão') i.60: "Monges, estes dois [tipos de erros] ultrajam o Buddha: Quais? Apresentar como definitivo (nithattha) um discurso [do Buddha] provisório (neyyattha); e apresentar como provisório (neyyattha) um discurso definitivo (nithattha)".

As palavras paramattha e sammuti são também encontradas nos sūtras canônicos, mas, como observado por D. Kalupahana (2006, p.332-333) em um sentido ainda não epistemológico, e sim, principalmente, ético. É somente nas MP (embora Williams [2001, p.87] afirme - sem apresentar provas textuais - que a distinção em questão surja "muito cedo nos desenvolvimentos do pensamento buddhista e, com certeza, no Abhidharma"), ou seja, no texto examinado neste pé de página, que os dois termos são utilizados para designar dois níveis de verdade. 
espiritual; o percurso cognitivo e existencial de cada um deles começava de diferentes pontos de partida - portanto, era necessário adaptar o ensinamento a tais diferentes níveis de compreensão ${ }^{16}$.

No entanto, a própria aplicação da distinção entre 'convencional' e 'último' resultou problemática, entre as várias escolas que surgiram depois do desaparecimento do Buddha. Controvérsias surgiram sobre a correta maneira de entender quais conceitos e teorias mereciam a qualificação de 'verdade definitiva' e quais fossem, ao contrário, as doutrinas só 'provisórias'.

As dificuldades derivavam da circunstância de que a doutrina do 'não-si', na formulação originária do Buddha, embora fosse suficientemente claro o que negava - a existência real de um núcleo substancial dentro de nós e dentro das coisas -, não deixava, contudo, igualmente claro o que afirmava, posto que afirmasse algo.

O Buddha, nos seus discursos, tinha, genericamente, reduzido a individualidade ao conjunto dos cinco 'agregados' (indicados anteriormente), cada um deles desprovido de um núcleo. Portanto, num primeiro nível de análise, podia-se concluir que o indivíduo (implicitamente pressuposto pelo próprio Buddha em alguns dos seus ensinamentos) seja uma realidade 'convencionalmente verdadeira', enquanto os cinco agregados são 'verdade última'.

Contudo, nos séculos que se seguiram à morte do Buddha, pareceu legítimo perguntar-se se os agregados fossem o limite extremo que um olhar analítico pudesse alcançar ou se, por sua vez, eles pudessem ser ulteriormente dissecados e investigados.

\subsection{Interpretação abhidharmika da doutrina das 'duas verdades': a teo-} ria dos dharma

Chegou-se assim - na fase 'escolástica' das escolas do Abhidharma - à conclusão de que os agregados resultam compostos de entidades atômicas, instantâneas e discretas: os dharma ${ }^{17}$. Estes são ligados entre eles por meio

16 A palavra upāya ('expediente', 'meio conveniente' ou, até, 'pedagogia') é a expressão com a qual é frequentemente indicada, no meio buddhista, a capacidade do ensinamento do Buddha de se adaptar a diferentes exigências e níveis intelectivos. E. Conze (1980, p.48), diz: "[Upāya,] 'Skill in means' is the ability to bring out the spiritual potentialities of different people by statements or actions which are adjusted to their needs and adapted to their capacity for comprehension.".

17 A palavra dharma (pāli dhamma), na linguagem filosófica e religiosa da Índia, tem um leque semântico que, a partir da raiz verbal $\sqrt{ } d h r$ ('segurar', 'manter'), se torna particularmente amplo. A.Hirakawa, (1993), p.45: "the term came to mean 'that which does not change'. It thus was applied to the ideas and norms that maintained the social and moral order. Besides good, virtue, and truth, from ancient times in India the term 'dharma' was used to refer to the customs and duties observed by people - in other words, the social order". Cf., também, J. Grimes (1996). 
de relações causais. Uma entidade complexa, como pode ser uma pessoa ou um objeto, é um agregado de inúmeros dharma (físicos e mentais) que, a cada instante, antes de desaparecer, causam o surgimento de novos dharma, da mesma tipologia (por exemplo, um determinado dharma material pode causar um outro dharma idêntico) ou de tipo diferente (por exemplo, um instante dhármico de 'volição' pode produzir um dharma de tipo 'sensação') ${ }^{18}$.

As numerosas escolas ${ }^{19}$ que surgiram nos séculos entre o parinirvāna ${ }^{20}$ do Buddha e o começo da era cristã diferenciavam-se entre elas no que diz respeito ao exato número e ao gênero de tipos de dharma existentes, à duração efetiva de cada um deles, ao exato funcionamento de seus poderes causais. No entanto, apesar dessas diferenças, todas as escolas abhidharmika compartilhavam a mesma ontologia atômico-pluralista.

As inovações no campo ontológico obrigaram a rever a questão epistemológica: o conceito de 'verdade última' foi redefinido, precisando-se agora como a realidade dos dharma, consequentemente relegando os próprios, mais genéricos 'agregados' (a dizer, os cinco skandhas) ensinados pelo Buddha - junto com as doutrinas que (por serem destinadas a uma audiência menos dotada) implicavam o conceito de 'si' - à 'realidade convencional'.

No âmbito buddhista, os dois principais significados são aquele de 'ensinamento fundamental do Buddha' (como 'visão correta da realidade' ou 'ser verdadeiro das coisas': nesse caso a palavra costuma ser transliterada com 'd' maiúsculo) e dharma (com 'd' minúscolo) no sentido, aqui em exame, de entidades últimas das quais os diferentes fenômenos são, em última análise, compostos.

Os agregados podem, então, ser dissecados em 'instantes' de realidade de diferentes tipologias (o numero exato dessas tipologias varia nas diferentes escolas. A escola Theravāda, por exemplo, conta com 82 tipos de dharma, enquanto a Sarvāstivāda, com 75).

O agregado 'forma material' (rūpa) é reduzido a dharma tais como: solidez, fluidez, calor, movimento, etc.; os outros quatro agregados, psíquicos, são dissecados em dharma como: ilusão, raiva, ciúme, remorso - exemplos, esses, de dharma 'não saudáveis'; há também vários dharma saudáveis: por exemplo, fé, equanimidade, esforço assíduo. Outros dharma, enfim, são 'gerais' e eticamente neutros: por exemplo, sensação, percepção, atenção.

18 A capacidade dos dharma engendrarem outros dharma da mesma tipologia, nas MP, é ilustrado por meio do exemplo de uma vela: a cada instante o dharma 'calor' que se manifesta como chama produz, antes de desaparecer, um outro dharma idêntico (o observador, não tendo percepção da instantaneidade de cada momento, só vê a flama como continuum, da mesma forma em que, assistindo a um filme, não percebemos que ele é composto de vários fotogramas; segundo um exemplo mais tradicional, quando uma tocha é movimentada em círculo rapidamente, vemos um círculo de luz que, na realidade, não existe). O processo de formação da manteiga a partir do leite é, por outro lado, o exemplo com o qual (nas mesmas MP) é ilustrado o caso de dharma que causam o surgimento de outros dharma de natureza diferente.

19 Tradicionalmente, as escolas abhidharmika são 18 (resultado de subdivisões ulteriores que se seguiram a um primeiro cisma, o entre Mahāsāṃghika e Sthaviravāda, que remonta ao Segundo Concílio, durante, segundo alguns, o começo do IV século a.C.). Provavelmente, existiram mais escolas do que esse número apontado, mas de muitas delas não temos nenhuma informação.

20 A morte física do Buddha é definida, nos textos buddhistas, como o seu ingresso no paranirvāna (literalmente, 'extinção suprema'). 
1.4. Interpretação mādhyamika da doutrina do 'não-si': a teoria da 'vacuidade'

Mas tudo isso, também, não foi considerado satisfatório e definitivo. No decorrer da história do pensamento buddhista, as escolas mahāyāna acharam que o conceito de dharma fosse discutível e incorreto, pois ele implicava um aspecto de substancialidade ${ }^{21}$; isto é, uma forma de individualidade e de autossuficiência, inconciliável com uma rigorosa aplicação da doutrina do 'não-si'.

Os próprios dharma, submetidos à rigorosa análise, revelam-se, enfim, vazios e inexistentes como realidade 'em si'.

O conceito de 'vacuidade' (śūnyatā), como visão última da realidade, foi adotado tanto pela escola Yogācāra quanto pela Madhyamaka. Sob o olhar analítico das escolas mahāyāna, qualquer entidade (não somente as entidades complexas, mas também as simples e atômicas, não importa se de tamanho mínimo e de duração instantânea) dotada de 'natureza própria' (svabhāva) e separada das outras é, em última análise, inexistente.

\subsection{Leitura niilista da teoria da 'vacuidade' e sua inconsistência}

Uma posição desse tipo é, evidentemente, arriscada: o perigo é de tornarse uma visão niilista do mundo. Afinal, o Madhyamaka é o desenvolvimento mais teórico e sistemático de uma série de escrituras - as que compõem a literatura prajñāpa ${ }_{\text {ramit }} \bar{a}^{22}$ - nas quais o uso de uma linguagem aparentemente

21 Sintetizando ao extremo o verbete 'sostanza' da 'Enciclopedia Garzanti di Filosofia' (p. 885-887) podese afirmar que, na história do pensamento ocidental, o conceito de 'substância' inclui, pelo menos, três aspectos: 1) A substância é algo que se mantém fixo e permanente ao mudar-se dos acidentes; 2) ela é o substrato das categorias a ela inerentes (ou seja, por exemplo, as qualidades sempre pertencem a uma substância); e, 3) a substância existe em si, sem depender, ontologicamente e conceitualmente, de outras substâncias: "Cada substância deve, com efeito, subsistir em si e ser concebida absolutamente, isto é, por si; ou seja, o conceito de uma substância não implica o conceito de uma outra substância" (B.Espinoza, Ethica more geometrico demonstrata).

Os primeiros dois desses três aspectos não são aplicáveis ao conceito de dharma: um dharma é, tipicamente, impermanente; a sua existência é instantânea. Em segundo lugar, o dharma não é substrato de qualidades ou de outras categorias; ele é, em si mesmo, uma qualidade ou uma propriedade (isto é: não existem dharma 'fogo' ou 'terra', e sim dharma 'calor' ou 'solidez'). A partir disso, alguns estudiosos (p.e., Sideritis, 2007, p.119), concluem que não seja possível aplicar aos dharma o conceito 'ocidental' de substância.

Todavia, o terceiro aspecto da ideia de 'substância' pertence plenamente ao conceito buddhista de dharma: uma das suas fundamentais características é a de possuir svabhāva, a dizer, 'natureza própria', essência ou autossuficiência. É justamente esse elemento de ser um possuidor de svabhāva que se torna alvo das críticas das escolas mahāyāna, e Madhyamaka em específico.

22 Os textos da prajñāāāramitā ('perfeição da sabedoria') são uma série de escrituras que, desde acerca o primeiro século a.C., começaram a circular nos meios monásticos buddhistas. Essas escrituras são apresentadas como autêntica, embora esotérica 'palavra do Buddha'. Verossimilmente (cf. Potter, 199699) ligadas à tradição Mahāsāṃghika, a qual surgiu depois do cisma do IV século a. C., elas se tornaram a base literária sobre a qual foi desenvolvida a filosofia das escolas mahāyāna. 
niilista é frequente e incisiva ${ }^{23}$. A questão, porém, é que o niilismo é uma doutrina que o próprio Buddha, junto à doutrina 'eternalista', convida explicitamente a evitar ${ }^{24}$. Defender uma posição niilista significa pôr-se direta e explicitamente em contraste com a palavra do Buddha.

Das duas escolas mahāyāna, a Yogācāra parece escolher uma visão filosófica que mais claramente consegue escapar do 'perigo' niilista, chegando a uma visão rigorosamente idealista ${ }^{25}$. $\mathrm{O}$ 'nada existe' vale somente no nível material: o que é vazio e não existe em si é o mundo dos objetos externos; da realidade externa pode-se falar apenas no sentido 'convencional'. A 'verdade última' é que existe somente a consciência indiferenciada: absoluta subjetividade, cujas internas diferenciações são, também, 'verdades convencionais ${ }^{26}$.

O Madhyamaka, pelo contrário, em nome de uma aplicação da doutrina do 'não-si', a qual pretende ser mais rigorosa, nega também a existência da subjetividade. O niilismo parece, portanto, inevitáve ${ }^{27}$. O percurso filosófico da teoria do 'não-si' levaria, enfim, à negação de tudo. O epílogo desse percurso parece ser que a 'verdade convencional' ou 'provisória' corresponda

23 Por exemplo, o Hṛdaya Sūtra ("Discurso do Coração"), talvez o mais conhecido entre os sūtra prajñāpāramitā, afirma que: "Na vacuidade não há forma material, nem sensação, nem ideação, nem volições, nem consciência; nem olho, orelha, nariz, língua, corpo, mente; nem formas [visíveis], sons, cheiros, gostos, objetos do tato e objetos mentais [...] não há ignorância, nem extinção da ignorância [...] não há decadência e morte, nem extinção de decadência e morte; não há sofrimento, nem surgimento [do sofrimento], nem extinção [do sofrimento], nem caminho [para a extinção do sofrimento]; não há alguma sabedoria, nem realização, nem não-realização" (Śāriputra śūnyatām na rūpam̉ na vedanā na saṃjñā na samskārāḥ na vijñānam. na caksuh-śrota-ghrāna-jihvā-kāya-minanāṃzi. na rūpa-śabda-gandharasa-sprașțavya-dharma [...]. na-avidyā na-avidyā-ksayo yāvan na jarā-maraṇaṃ na jarā-maraṇa-ksayo. na duḥkha-samudaya-nirodha-mārgā. na jñānam, na prāptir na-aprāptị̣).

24 "O mundo, o Kaccana, é geralmente baseado nessas duas concepções: o eternalismo (sassataditthi) e o niilismo (ucchedaditthi). Mas quem considera, o Kaccana, à luz de um reto conhecimento e conforme a realidade, o nascimento do mundo, fica imune de qualquer forma de niilismo no que diz respeito ao mundo. E quem considera, o Kaccana, à luz de um reto conhecimento e conforme a realidade, a dissolução do mundo, ele fica imune de qualquer forma de eternalismo no que diz respeito ao mundo [...] A teoria segundo a qual tudo existe é um extremo, o Kaccana, e da mesma forma a conforme a qual tudo não existe. Pois bem, o Kaccana, o Tathāgata [Tathāgata, literalmente 'O que assim foi', é um dos epítetos do Buddha], refutando ambos esses dois extremos, ensina o Dhamma de meio" (Kaccanagottasutta ["O discurso de Kaccanagotta"]; Saṃyutta Nikāya, 2.12.2.5). Tradução (do inglês) nossa.

25 Os outros nomes com os quais essa escola é conhecida dizem, mais explicitamente, respeito à sua propensão idealística: Cittamātra ('Só mente'), Vijñaptimātra ('Só representação cognitiva') e Vijñānavāda ('Ensinamento sobre a consciência').

26 De qualquer forma, "The definitions of the two truths in the Mind-Only system are not among the most illuminating definitions" (G. Newland, 1999, p.54).

27 Com efeito, as interpretações do Madhyamaka como uma filosofia niilista - aliás, o mais extremo niilismo que já foi concebido pelo pensamento humano - existem desde os tempos de Nāgārjuna até os dias de hoje. As primeiras leituras de Nāgārjuna no Ocidente - por exemplo aquela, pionéira, de M. Burnouf (1844), a de J. H. Kern (1889) ou a de A. B. Keith (1923) -, no século XIX, viram na sua filosofia um puro niilismo. Depois de quase um século de interpretações 'cépticas', 'absolutistas', 'descontrutivistas', etc. do seu pensamento, mais recentemente, a leitura niilista vem reaparecendo, por exemplo nos estudos de T. Wood (1994) F. Tola - C. Dragonetti (1995) ou D. Burton (2001). 
a todos os discursos que falam de alguma coisa, enquanto a 'verdade última' é que nada existe e que de nada se pode falar.

Entretanto, a conclusão de que o Madhyamaka seja uma escola niilista não seria, segundo a maioria dos seus interpretes, satisfatória: em primeiro lugar porque o niilismo ontológico parece uma posição filosoficamente insustentável ${ }^{28}$; segundo, porque, como já dito antes, não se pode sustentar o niilismo sem incorrer na flagrante contradição da palavra do Buddha; terceiro, porque os pensadores mādhyamika se recusam de ser rotulados como 'niilistas'29.

É sempre possível, naturalmente, para manter a interpretação niilistica do Madhyamaka, pensar que filósofos como Nāgārjuna ou Candrakīrti fossem, mesmo, heréticos; ou talvez pouco acurados e atentos, ao ponto de tornar-se niilistas 'involuntariamente', talvez por não terem profundamente entendido os ensinamentos do Buddha (porém, contra essa possibilidade, além de muitas outras considerações, há que o único discurso do Buddha citado por Nāgārjuna nas MMK é justamente o Kaccayanagotta sutta, ou seja, o sūtra citado da nota de pé de página 25 desse artigo - no qual o Buddha convida explicitamente a evitar o niilismo).

De qualquer forma, a definição do que devemos considerar 'ultimamente' e do que 'convencionalmente' verdadeiro na filosofia mädhyamika é problemático e aberto. Posto que 'a existência do puro nada' não possa ser a verdade última e definitiva ensinada por Nāgārjuna, o que devemos, entretanto, considerar 'verdade última' na sua filosofia?

Não pretendemos, aqui, como já declarado, entrar em tão delicada questão, nem, muito menos, tentar solucioná-la; as possíveis soluções do dilema da definição da verdade na filosofia mädhyamika (uma definição

28 Talvez sejam sustentáveis niilismos axiológicos, existenciais ou epistemológicos, mas o niilismo ontológico é uma posição que, sob um ponto de vista lógico, parece equivaler a puro absurdo: a 'existência do nada' ou a 'não existência do ser' são, de alguma maneira, uma forma de existência (a existência de uma negação, que pressupõe, por sinal, a existência de um negador).

Há discussões em que é debatido se os discursos de Nāgārjuna incorrem no 'paradoxo do mentiroso' ("Esta frase é falsa": é uma frase verdadeira ou falsa?) - ou seja, em um tipo de afirmação que é verdadeira, só se falsa; e falsa, se verdadeira. Independente das possíveis soluções oferecidas (por exemplo por de Buridano, Tarski, Prior ou Russell) a tal paradoxo, I. Mabbett (1996) argumenta, convincentemente, que Nāgārjuna não cai nessa aparente contradição lógica, à medida que a sua tese da 'vacuidade de todas as coisas' não é equivalente à afirmação da falsidade delas.

29 No Vigrahavyāvartanī ('Extermínio dos erros'), repetidamente, Nāgārjuna rebate a acusação de ser 'niilista' ou defensor de qualquer outra tese - VV.29: "Se eu tivesse alguma tese, então, eu estaria em contradição; porém, não há nenhuma tese que me pertence e, por isso, não há nenhuma contradição" (yadi kācana pratijñā syānme tatá eșa me bhaveddoșaḥ / nāsti ca mama pratijñā tasmānnaivāsti me doṣaḥ //); VV.63: "Eu não nego nada, nem há nada a ser negado. Por isso, quando você fala 'tu negas', você me calunia" (pratiședhayāmi nāhaṃ kiṃcit pratiședhyamasti na ca kiṃcit / tasmātpratiședhayasītyadhilaya eșa tvayā kriyate //). 
que, possivelmente, evite a conclusão niilista, mas que, ao mesmo tempo, seja compatível com a ideia de 'vacuidade' de todas as coisas) são muitas e variadas.

O ponto desse artigo é que, qualquer solução interpretativa, para ser crível, não pode menosprezar o contexto histórico-filosófico no qual o discurso de Nāgārjuna se desenvolve. Antes de qualquer outra consideração lógico-linguística e, mais geralmente, filosófica - indispensável para entender a posição de Nāgārjuna, é fundamental examinar o uso que, dentro da tradição filosófica que o precede e o acompanha, é feito das palavras e dos conceitos dos quais a escola Madhyamaka se serve para expressar seus pontos de vista.

Em específico, a primeira parte das MP apresenta um evidente paralelismo formal (a dizer, uma semelhança na estrutura do discurso) e terminológico com o capítulo 24 das MMK: qualquer séria reflexão sobre o verdadeiro significado das ideias de 'vacuidade' e de 'verdade última' na concepção de Nāgārjuna deve ter, entre os seus pontos de partida, as conclusões que o rei Milinda e o monge Nāgasena alcançam no decorrer do seu diálogo.

\section{Milinda Pañha, 25-28 e Mūlamadhyamikakārikās, 24: Semelhanças Formais}

\subsection{Ontologia e ética em contraste nas MP e em MMK.24}

As 'Perguntas do rei Milinda' são uma escritura de enorme relevância na história do pensamento buddhista ${ }^{30}$. Trata-se de um texto - cuja redação (provavelmente compósita) deve se situar na época entre o primeiro século a.C. e o segundo século d. $C^{31}$ - que relata acerca de um diálogo entre o rei indogrego Milinda ${ }^{32}$ e o monge buddhista Nāgasena. Não é um texto 'canônico', no sentido de que não pertence a nenhum dos tradicionais 5 nikāyas dos quais se compõe o 'cânone' buddhista ${ }^{33}$. No entanto, é uma escritura cuja autoridade parece transversal a todas as escolas buddhistas, não sendo reconhecida como texto particular de nenhuma tradição em específico.

30 O eminente buddhologista T. Rhys Davids (1890, p. XLVIII) chegou a definir as MP como a "obra principal da prosa indiana".

31 Cf. R. Gnoli (2001, p.CXIV). A hipótese mais recente de redação, portanto, faz das MP um texto da mesma época de Nāgārjuna.

32 Milinda é o rei grego Menandro I 'o sábio', que governou entre 160 e 130 a.C. acerca, na região leste (Reino Indo-grego, correspondente a algumas províncias do atual Paquistão) do império grego de Bactriana.

33 A tradição buddhista birmana, de qualquer forma, o inclui no Khuddaka Nikāya ('Coleção menor'), ou seja, considera-o um texto canônico (cf. Gnoli, 2004, p. CXIII). 
O diálogo se abre com o rei Milinda que pergunta ao monge pelo seu nome; a resposta, sem muitos preâmbulos, leva-nos imediatamente à questão da ausência de individualidade:

“ - Sua majestade, sou conhecido como Nāgasena. Meus confrades se dirigem a mim chamando-me de Nāgasena. Qualquer nome que os pais derem aos seus filhos - Nāgasena, Sūrasena, Vīrasena, Sīhasena -, se trata somente de um apelido, de uma noção comum, de uma designação, de um uso corrente. 'Nāgasena' é somente um nome, porque nenhum indivíduo (puggala) é aqui presente." ${ }^{34}$

Essas linhas sintéticas correspondem ao que, ao longo dos 27 capítulos das MMK, é apresentado analiticamente: o sujeito individual que temos a sensação de ser, e as entidades objetivas separadas com as quais pensamos nos relacionar, são somente nomes, designações convencionais, às quais não corresponde nada de ultimamente real.

Porém, evidentemente, essa tese presta-se a uma fundamental objeção. O rei Milinda a expressa da seguinte forma:

“ - Se, venerável Nāgasena, aqui não há pessoa alguma, quem será, então que lhes oferece roupa, comida, alojamento, remédios contra as doenças e ferramentas? Quem utiliza essas coisas? Quem exerce as virtudes morais? Quem se dedica à meditação? Quem realiza o caminho, o fruto e o nibbāna? Quem mata? Quem pega o que não lhe foi dado? Quem tem uma errada conduta sexual? Quem fala mentiras? Quem toma bebidas tóxicas? Quem cumpre as cinco ações de imediata retribuição [cármica]? Enfim, não há nem o que é saudável (kusala) nem o que é não saudável (akusala), não há quem cumpre ações saudáveis ou danosas, não há quem as faz cumprir, nem há resultado, maturação de ações virtuosas e não virtuosas: se, por exemplo, venerável Nāgasena, não existisse quem mate, também a ação de matar não existiria. Além disso, venerável Nāgasena, você não tem mestre, preceptor, ordenação."

O capítulo 24 das MMK, embora de forma mais esquemática, apresenta uma objeção muito semelhante à das MP:

1. Se tudo neste [mundo] é vazio, não há [portanto] nem aparição nem desaparição de nada: [isso] implica a sua [asserção da] inexistência, das Quatro Nobres Verdades; 2. Reto conhecimento, eliminação [dos falsos pontos de vista], meditação e realização, não existindo as Quatro Nobres Verdades, não seriam possíveis;

3. Não existindo esses [quatro momentos], os quatro nobres frutos ${ }^{35}$ seriam também inexistentes; os frutos não existindo, não existiria nenhum gozador dos frutos, nem os candidatos a gozá-los;

34 Esse e todos os trechos das MP citados são traduções nossas da tradução em italiano (do original em pāli) de F. Sferra (em Gnoli [2004], Vol I, pp.103-204).

35 Os quatro nobres frutos (ārya-phala) são: 'entrada na correnteza', 'condição de quem vai re-nascer só mais uma vez', 'condição de estar no último re-nascimento' e 'condição de consecução da iluminação'. 
4. Se não existem os oito tipos de pessoas ${ }^{36}$, também não existe o $S a m g h a^{37}$; e não existindo as Quatro Nobres Verdades, também o verdadeiro Dharma ${ }^{38}$ não seria visível.

5.6. E se não há Dharma e Samgha, como poderia haver buddha? Dessa forma, afirmando a vacuidade, você rejeita também as três jóias ${ }^{39}$, e também rejeita a realidade dos frutos, o correto $\left(\right.$ dharma $\left.^{40}\right)$ e o errado (adharma) e toda a ordem convencional (samvyavahāra) das coisas mundanas ${ }^{41}$.

Conforme sua atitude tipicamente sistemática, Nāgārjuna apresenta, ordenadamente, (partindo dos alicerces da visão buddhista do mundo - ou seja, das Quatro Nobres Verdades - e chegando, só no final, à problemática ética) a objeção a qual, na pergunta de Milinda, é apresentada em um estilo mais discursivo e desordenado, e com um enfoque maior nas consequências éticas finais da negação da individualidade: sem um 'si' individual, quem seria o sujeito das ações virtuosas e não virtuosas?

\subsection{As duas verdades em MMK.24}

A resposta de Nāgārjuna à objeção apresentada nos primeiros seis versos do capítulo 24 é uma passagem crucial das MMK. Ele fala:

7. A esse ponto, nós declaramos que você não entende o sentido da vacuidade, a vacuidade [em si] e seu objetivo. Por isso, você é perturbado [por ela];

8. O ensinamento do Dharma por parte dos buddhas é baseado sobre duas verdades: a verdade da convenção mundana (loka-sajvrti-satyam) e a verdade última (paramārthatah);

9. Os que não entendem a diferença entre tais duas verdades, não entendem a realidade profunda inerente ao ensinamento do Buddha ${ }^{42}$.

Dado o grande número de soluções (entre elas frequentemente contraditórias ou contrárias) fornecidas à questão do que seria 'verdade

36 Ou seja, os quatro que já conseguiram os frutos da prática e os quatro que estão no caminho para consegui-los.

37 Comunidade dos monges.

38 Ensinamento do Buddha (cf.nota 18).

39 As três jóias (triratna) são, justamente, o Samgha, o Dharma e o Buddha.

40 Temos, aqui, mais um significado da palavra dharma.

41 1. Yadi śūnyam idaṃ sarvam udayo nāsti na vyavaḥ / caturṇām ārya-satyānām abhāvas te prasajyate

2. Parijñā ca prahāṇm ca bhāvanā sākșikarma ca / caturnā̄m ārya-satyānām abhāvān nopapadyate

3. Tad abhāvān na vidyante catvāryārya-phalāni ca / phalābhāve phalasthā no na santi pratipannakāh

4. Saṃgho nāsti na cet santi te 'șțau purușa-pudgalāḥ / abhavāccārya-satyānāṃ saddharmo 'pi na vidyate

5. Dharme cāsati saṃghe ca katham buddho bhavișyati / evam trīnì api ratnāni bruvāna ḥ pratibādhase

6. Sunnyatāṃ phala-sadbhāvam adharmam dharmam eva ca / sarva-saṃyavahārāmśs ca laukikān pratibādhase

42 7. Atra brūmah śūnyatāyāṃ na tvam vetsi prayojana m / śūnyatāṃ śūnyatārthaṃ ca tata evam vihanyase

8. Dve satye samupāśritya buddhānām dharmadeśanā / lokasaṃu ritisatyam ca satyam ca paramārthatah

9. Ye 'nayor na vijānanti vibhāgam satyayadvayo h / te tattvam na vijānanti gambhiram buddha-śāsane 
convencional' e que 'verdade última' no buddhismo mādhyamika, podese concluir que, pelo menos algum dos intérpretes de Nāgārjuna, de fato, não entendeu essa diferença (a menos que alguém não tente argumentar, contrariamente a qualquer lógica e evidência textual, que cada uma das duas verdades tenha um leque semântico que suporte qualquer tipo de interpretação), nem, portanto, "a profunda realidade ínsita no ensinamento do Buddha".

De qualquer forma, o fato de que a 'vacuidade' está de alguma maneira relacionada à 'realidade última', parece inquestionável. Os pontos a serem esclarecidos são: 1) qual é o exato sentido dessa relação de śūnyatā com paramārtha-satya? 2) Se o conceito de 'vacuidade' é uma qualificação da 'verdade última', esse seria a única qualificação possível de paramārthasatya, ou essa última seria qualificável também por meio de outros conceitos (que, evidentemente, deveriam ser equivalentes conceituais da vacuidade) ${ }^{43}$ ? 3) O que exatamente significa 'vacuidade'? Pura ausência de ser ou ausência de um tipo de ser (logo, existência de um modo de ser diferente do aparente)?

Unicamente está certo que a correta compreensão da vacuidade é, segundo Nāgārjuna, uma tarefa fundamental, cujo desatendimento constitui um obstáculo certo no caminho rumo à evolução espiritual:

11. A vacuidade mal-entendida perverte o homem pouco inteligente, como uma cobra mal apanhada ou uma fórmula mágica mal pronunciada ${ }^{44}$.

\subsection{Receios niilistas nas MP}

Dando continuidade à nossa hipótese - de que a análise das MP possa fornecer indicações para esclarecer pontos obscuros das MMK - vemos como prossegue o diálogo entre Milinda e Nāgasena, que interrompemos com a objeção do rei à paradoxal declaração do monge de que a individualidade é algo de somente convencional e nominal.

O rei Milinda, um pouco inesperadamente (com efeito, o mais lógico seria que fosse Nāgasena - que sustenta a tese da própria inexistência - a fazer as perguntas e alcançar a conclusão que se seguem) começa a perguntar se a individualidade de Nāgasena possa ser identificada com partes e órgãos do corpo:

43 Um possível candidato ao papel de 'equivalente conceitual' de śūnyatāé, na opinião de vários intérpretes de Nāgārjuna, o conceito de 'originação dependente' (pratītyasamutpāda); um conceito cuja história dentro da filosofia buddhista é longa e complexa, ao ponto de não permitir, no espaço desse artigo, nem uma abordagem sumária. Somente vale lembrar que, pelo menos em dois pontos cruciais das MMK (os dois versos introdutório e o verso 24.18), Nāgārjuna parece oferecer uma base textual à hipótese tanto de que a 'originação dependente' seja a 'verdade última', quanto de que ela seja um equivalente ou um sinônimo de 'vacuidade'.

44 11. Vināśayati durd ṛșțā śūnyatā mandamedhasaṃ / sarpo yathā durg ḥîno vidyā vā dușprasādhitā 
“-Venerável Nāgasena, são, por acaso, os cabelos 'Nāgasena'?

- Não, majestade!

- 'Nāgasena' são, por acaso, os pelos?

- Não, majestade!

- São, por acaso, as unhas, os dentes, a pele, a carne, os músculos, os ossos, a medula, os rins, o coração, o fígado, as membranas, o baço, os pulmões, os intestinos, o mesentério, o estômago, os excrementos, a bile, o flegma, o pus, o sangue, o suor, a gordura, as lágrimas, o soro, a saliva, o muco, o liquido sinovial, a urina, o cérebro na cabeça, são por acaso - digo - essas coisas 'Nāgasena'?

- Não, majestade!"

O rei, portanto, passa a perguntar se a corporeidade no seu conjunto, ou qualquer dos outros quatro skhanda, permite individuar o 'si' do seu interlocutor:

“-Venerável, 'Nāgasena', por acaso, é a forma material (rūpa)?

- Não, majestade!

- 'Nāgasena' são, por acaso, a sensação (vedanā), a ideação (sañ̃̄a), as atividades volitivas (sankhāra), a consciência (viñ̄̃āna)?

- Não, majestade!

- Mas, então, venerável, talvez 'Nāgasena' seja o conjunto de forma material, sensação, ideação, atividades volitivas, consciência?

- Não, majestade!

- Mas, então, venerável, 'Nāgasena' é outra coisa afora de forma material, sensação, ideação, atividades volitivas, consciência?

- Não, majestade!"

A conclusão, enfim, é inevitável: essa perfeitamente coincide com a tese inicial apresentada por Nāgasena - a individualidade, não podendo ser identificada, não existe:

“ - Embora eu, venerável, esteja repetidamente perguntando quem é Nāgasena, não vejo nenhum Nāgasena! Nāgasena, venerável, é somente uma palavra (sadda). Por isso, quem está aqui? Você, venerável, está utilizando uma palavra falsa e mentirosa! Nāgasena não existe".

A evidência lógica do 'não-si', contraposta à convicção instintiva na nossa individualidade, tem um efeito perturbador: o rei Milinda parece confuso, a ponto de esquecer que era o próprio Nāgasena, no começo do diálogo, a afirmar que o próprio nome carecia de denotação.

\subsection{Verdade última e convencional nas MP}

A vacuidade mal-entendida, como lembrado por Nāgārjuna, é algo de extremamente perigoso; Nāgasena, portanto, está devendo uma explicação para o rei Milinda, para que ele não 'pegue a cobra' de forma errada. E essa explicação, 
baseada na dicotomia entre significado 'último' e 'convencional', segundo a hipótese aqui apresentada, deve ter peso e influência na maneira com a qual o próprio Nāgārjuna entende essas mesmas duas categorias epistemológicas.

Nāgasena, conforme um estilo plenamente 'maiêutico', quer que seja o mesmo rei, por meio do seu próprio raciocínio, a chegar à visão correta. $\mathrm{O}$ monge, portanto, começa perguntando a Milinda se ele chegou naquele lugar a pé ou por um meio de transporte;

“- Eu, venerável, não vim a pé, mas de carruagem.

- Se você veio de carruagem, me mostre a carruagem. É, por acaso, o timão a carruagem, majestade?

- Não venerável!

- A carruagem, talvez, seja o eixo?

- Não venerável!

- A carruagem, talvez, sejam as rodas?

- É, por acaso, o chassi $[\ldots]$, a vara da bandeira $[\ldots]$, o jugo $[\ldots]$, as rédeas $[\ldots]$, o aguilhão para empurrar o gado?

- Não venerável!

- Mas então, majestade, a carruagem talvez seja algo de diferente além de chassi, vara da bandeira, jugo, rédeas, aguilhão para empurrar o gado?

- Não venerável!

- Embora eu esteja repetidamente perguntando o que é a carruagem, não vejo nenhuma carruagem. A carruagem é somente uma palavra, majestade. Que carruagem há aqui? Você, majestade, está utilizando uma palavra falsa e mentirosa. A carruagem não existe!

Você, majestade, é o rei principal do inteiro Jambudīpa ${ }^{45}$ : está com medo de quem, por falar uma mentira?"

A desestruturação da visão ordinária do mundo, a essa altura, é completa: não somente a dimensão subjetiva é vazia de um núcleo individual e, portanto, não existe em si, mas também no mundo dos objetos não conseguimos achar nada de substancial, cada coisa podendo ser reduzida às partes que a compõem.

Significa, tudo isso, niilismo? A conclusão de que não existe nenhuma individualidade subjetiva nem objetiva equivale a dizer que não existe definitivamente nada?

É o próprio Milinda que, depois da apertada troca de perguntas e respostas, chega a vislumbrar a realidade:

“ - Eu, venerável Nāgasena, não digo nenhuma mentira, desde que é em virtude do timão, do eixo, das rodas, do chassi, da vara da bandeira, do jugo, das rédeas, do aguilhão para empurrar o gado que a carruagem existe como apelido, noção comum, designação, uso corrente, nome." 
Essa conclusão do rei é uma repetição só aparente das primeiras palavras de Nāgasena, quando o monge negava a sua própria existência como individuo. Nas palavras de Milinda, há algo de diferente: 'carruagem' é algo somente nominal e, podemos dizer, convencional ${ }^{46}$, mas é algo, que tem sua razão de ser nas partes que o compõem. Até agora, o ponto de partida e a conclusão do diálogo eram que nem Nāgasena, nem a carruagem existiam. Aqui, a perspectiva é outra: a carruagem existe como noção comum, ou seja, é uma 'verdade convencional'.

Nāgasena pode, agora, aplicar o raciocínio do rei à própria pessoa, da qual antes tinha sido declarada a não existência:

“ - Muito bem, majestade, você sabe o que é uma carruagem! As mesmas considerações valem para mim também. Com efeito, é em virtude dos cabelos, pelos, unhas...e em virtude de forma material, sensação, ideação, atividades volitivas e consciência que Nāgasena existe como apelido, noção comum, designação, uso corrente, nome. Segundo o ponto de vista absoluto (paramattha), aqui não há pessoa. Isso, majestade, foi também falado pela monja Vajirā à presença do Beato:

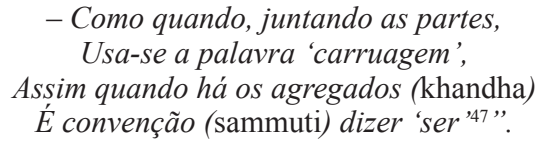

A conclusão da primeira parte do diálogo (a essa se seguirão dezenas de outras páginas, em que serão abordados alguns detalhes da doutrina do nãosi, além de outros assuntos) é, portanto, muito clara: 'verdade convencional' é o que aparece ao olhar ordinário: uma realidade de entes, objetivos e subjetivos, individuais e separados; 'verdade última' é que nenhum de tais entes existe como aparece. Não há, nas MP, uma caracterização positiva de um verdadeiro modo de ser das coisas, a dizer, a tentativa de descrição de um nível de realidade que verdadeiramente exista, além das aparências. As partes constitutivas, sobre as quais conceitos e nomes convencionais são fundados, não são definidas 'verdade última'. 'Verdade última', na conclusão das MP, é somente que 'aqui não há pessoa'.

46 Observemos que, de qualquer forma, a palavra pāli sammuti (sânscrito saṃnịti), traduzível como 'convencional', recorrente na literatura mādhyamika (em frequente conjunção com paramārtha, pāli, paramattha, 'última', 'suprema' ou 'definitiva'), não é encontrada nessa parte do texto das MP (onde se fala de 'noção comum', 'uso corrente', etc., mas não, explicitamente de 'convenção'), a não ser na citação (do Saṃyutta Nikāya) da monja Vajirā. Somente no quarto livro das MP, p.226, (provavelmente de redação posterior aos primeiros três, encontramos sammuti, em oposição a paramattha): “'Isto sou eu', 'isto é meu' são apenas opiniões convencionais (sammuti), não verdade última (na paramatto)"

47 Vajirā Sutta ("Sutta da [monja] Vajirā”) Saṃyutta Nikāya, V.10.6. 


\section{Conclusão}

Os resultados da análise efetuada até agora podem ser sintetizados como se segue.

A aparente contradição de alguns dos discursos iniciais do Buddha que propõem uma metafísica antissubstancialista e uma ética aparentemente centrada no conceito de substância individual - deu lugar, na reflexão buddhista sucessiva ao desaparecimento do Buddha, a uma epistemologia baseada na teoria das duas verdades.

Quanto ao conteúdo da primeira dessas duas verdades, a convencional (saṃvrti), na tradição filosófica que precede e acompanha o desenvolvimento mahāyāna do pensamento buddhista, não encontramos divergências: 'verdade convencional' é o mundo fenomênico: um mundo plural, de pessoas e de coisas, cada uma delas aparentemente dotada de substancialidade e individualidade.

Com relação à definição da 'verdade última', pelo contrário, as filosofias pré-mahāyāna apresentam duas tendências bem distintas: a primeira é a das escolas abhidharmika, de considerar ultimamente reais os dharma - instantes indivisíveis de realidade, discretos, cada um dotado de uma natureza própria (física ou psíquica) específica, componentes últimos de todos os entes complexos de que se compõe a realidade convencional. A segunda tendência, evidente nas MP, é aquela de tratar apofaticamente o plano da 'verdade última': objetivo do monge Nāgasena, ao longo do diálogo com o rei Milinda, é o de demonstrar o que paramārtha satya não é, sem oferecer alguma caracterização positiva dela.

Essas duas maneiras - uma catafática, a outra apofática - de tratar a temática da 'verdade última' são aquelas que definem os termos e o nível do debate epistemológico da época de Nāgārjuna e que, portanto, devem ser consideradas uma fundamental referência da reflexão dele.

Vários estudiosos contemporâneos, mesmo reconhecendo que o mestre mādhyamika rejeita a caracterização substancialista de 'verdade última' oferecida pelas escolas abhidharmika, no entanto, acreditam que ele compartilhe com aquelas escolas uma abordagem catafática ao conceito de paramārtha satya. Essa seria, portanto, de alguma maneira, definível: como 'absoluto', como 'relatividade universal', como 'Um'48 ou até - enfatizando

48 As apresentações do pensamento de Nāgārjuna-decisivas, por sinal, para a difusão e para a interpretação do Madhyamaka no Ocidente - feitas por estudiosos como Th. Stcherbatsky e T. R. V. Murti (1959) oferecem uma caracterização positiva da 'verdade última' em Nāgārjuna. Por exemplo: "In Hīnayāna, we have a radical pluralism; in Mahāyāna, we have a radical monism...The unique reality, according to Mahāyāna, cannot be caracterized in words (anirvacanīya), but a hint of it may be find in the following descriptions. It is the Whole of all wholes; it is the element of all elements [...], as their relativity (śūnyatā), as 'thisness' [...], as 'suchness'...Nāgārjuna asserted that there was not a shade of difference between 
os significados de 'zero' e de 'ausência' presentes na palavra śūnyatā - como 'nada', pura 'ausência de ser' 49 .

Contra tal tendência interpretativa, outros estudiosos de Nāgārjuna ${ }^{50}$ acreditam que a sua maneira de tratar paramārtha seja somente apofática - só pode ser dito o que não é ultimamente verdadeiro: isto é, qualquer visão da realidade que se baseie na percepção ou na concepção de algo de substancial e individual. Os poderosos instrumentos conceituais da 'vacuidade' (śūnyatā) e da 'originação dependente' (pratītyasamutpāda), longe de serem uma descrição da verdade última, só teriam a função de desestruturar e destruir as visões do mundo - a ordinária, mas também aquela, mais elaborada, das escolas filosóficas abhidharmika - baseadas em qualquer ideia de 'si'.

Entre outros possíveis pontos a favor dessa segunda hipótese interpretativa, este artigo enfatizou o paralelismo entre MMK.24 e a primeira parte das MP - um texto evidentemente apofático em relação a paramārtha. A semelhante construção e desenvolvimento do discurso entre os dois textos sugere que as MMK tenham uma maneira parecida de entenderem a dimensão da 'verdade última'.

Essa última, apesar de não poder ser aprendida ou descrita pelo raciocínio filosófico, fundado na convenção linguística e conceitual, pode, porém, de alguma maneira, ser alcançada a partir daquele raciocínio, uma vez que, "sem fundar-se na convenção (vyavahāra), a realização última (paramārtha) não pode ser mostrada" ${ }^{51}$.

Os discursos rigorosamente lógico-conceptuais feitos por Nāgārjuna, sem a possibilidade de dizer algo a respeito da 'verdade última', visariam levar o adepto da escola Madhyamaka à superação da lógica e da conceptualização e, com isso, à fruição, não discursiva e não conceptual, da própria 'verdade última'.

the Absolute and the Phenomenal, between Nirvāṇa and Saṃsāra. The universe viewed as a whole is the Absolute, viewed as a process, it is the phenomenal" Th. Stcherbatsky (2003), p.71.

49 Cf. nota 27

50 P.e., C. Huntington (1989), D. Seyfort Ruegg (2000), J. Garfield (2003), ou B. K. Matilal (2002, pp.4749), que sugere que as MMK pertençam àquela tipologia de discussão filosófica que, na tradição da escola Nyāya (a escola indiana, arqui-rival da Madhyamaka, mais comprometida com a lógica e com as regras do debate filosófico), é classificada - e criticada - como vitaṇdā ('objeção cavilosa'): um tipo de argumentação negativa que só procura confutar teses, sem estabelecer e defender alguma própria contratese. As outras duas tipologias apontadas nos Nyāya-s $\square$ tra são o debate de tipo vāda (propriamente 'discurso', 'argumento', 'explicação'), cuja finalidade é a determinação da verdade, e o jalpa (também, basicamente, 'discurso', mas de valor inferior), no qual só se visa ganhar a disputa.

51 MMK.24.10: Vyavahāram anāśritya paramārtho na deśyate 


\section{Referências bibliográficas}

Fontes primárias:

NĀGĀRJUNA, Mūlamadhyamikakārikā (Versos fundamentais do Caminho do Meio). Texto sânscrito em: Pandeya, R., Delhi, Mlbd, 1983. Texto sânscrito e tradução em inglês: Kalupahana, D.J., Delhi, Mlbd, 1986.

NĀGĀRJUNA Vigrahavyāvartan̄̄ (O extermínio dos erros). Texto sânscrito e tradução em inglês: Bhattacharya, K., Delhi, MLBD, 1978.

Milindapañha (Perguntas de Milinda). Tradução em italiano em 'La rivelazione del Buddha', Vol. I, org. por R. Gnoli, Milano, Arnoldo Mondadori, 2004.

Hṛdaya Sūtra (Sütra do coração). Texto sânscrito e tradução em italiano em E. Conze, 'I libri buddhisti della sapienza', Roma, Ubaldini, 1976.

Añguttara Nikāya (Coletânea [dos discursos] em progressão). Tradução em inglês em http://tipitaka.wikia.com/wiki/Sutta_Pitaka

Majjhima Nikāya (Coletânea [dos discursos] de médio tamanho). Tradução em inglês em http://tipitaka.wikia.com/wiki/Sutta_Pitaka

Samyutta Nikāya (Coletânea [dos discursos] reunidos). Tradução em inglês em http:// tipitaka.wikia.com/wiki/Sutta_Pitaka

Fontes secundárias:

AA.VV. - Enciclopedia Garzanti di Filosofia - Milano, Garzanti - 1981

BURNOUF, M. - Introduction à l'histoire do Buddhisme Indienne - Paris, Institute de France \& C., 1844.

BURTON, D. - Emptiness appraised - Delhi, Motilal Banarsidass, 1999.

CHEETMAN, E. - Fundamentals of mainstream Buddhism - Boston, Tuttle, 1994.

CONZE, E. - A Short History of Buddhism - Oxford, Oneworld, 1993.

GARFIELD, J. - Empty words - Oxford, University Press, 2003.

GNOLI, R. (org.) - La rivelazione del Buddha - Milano, Mondadori, 2004.

GRIMES, J. A. - A concise dictionary of Indian philosophy: Sanskrit terms defined in English - Albany, State University of New York Press, 1996.

HAYES, R. - "Nagarjuna's appeal" - Journal of Indian Philosophy 22.4, 1994.

HIRAKAWA, A. - A history of Indian Buddhism - Delhi, Motilal Banarsidass 1993

HUNTINGTON, C. - The emptiness of emptiness - Delhi, Motilal Banarsidass 1989.

KEITH, A.B. - Buddhist Philosophy of India and Ceylon - Oxford, 1923.

KERN, J.H. (1889) - Manual of Indian Buddhism - Strasbourg, 1896.

MABBETT, I. - "Is there Devadatta in the house - Nagarjuna's vigrahavyavartani and the liar paradox" - Journal of Indian Philosophy, 24.3, 1996.

MATILAL, B.K. - Mind, language and world: the collected essay of B.K.Matilal Oxford, University Press, 2002.

MONIER-WILLIAMS, M. - Sanskrit-English dictionary - New Delhi, Marwah Publications, 1986. 
MURTI, T.R.V. - The central philosophy of Buddhism - London, Allen \& Unwin, 1959.

NEWLAND, G. - Appearance and Reality - Ithaca (NY), Snow Lion Pub., 1999.

POTTER, K. (org.) - Encyclopedia of Indian Philosophies, Vol. VII: Abhidharma Buddhism to 150 A.D.; Vol: VIII: Buddhist Philosophy from 100 to 350 A.D. - Delhi, Motilal Banarsidass, 1996/1999.

RHYS DAVIDS, T. - The question of king Milinda - Oxford, 1890.

ROBINSON, R.H. - "Did Nāgārjuna really refute all philosophical views?" Philosophy East and West, 22 (3), 1972.

ROSS REAT, N. - "Historical Buddha and his teachings" - Encyclopedia of Indian Philosophies, Vol. VII: Abhidharma Buddhism to 150 A.D.; Delhi, Motilal Banarsidass, 1996/1999.

RUEGG, D. S. - "Some reflections on the place of philosophy in the study of Buddhism" - Journal of International Association of Buddhist Studies, 1995.

RUEGG, D. S. - Three Studies in Indian and Tibetan Madhyamaka Thought, Arbeitskreis für Tibetische und Buddhistische Studien, Universität Wien, 2000.

SIDERITS, M. 2007 - Buddhism as philosophy - England, Ashgate, 2007.

STCHERBATSKY, T. - The conception of buddhist nirvāna - Leningrado, 1927; reimpressão: Delhi, Motilal Banarsidass, 2003.

TOLA, F. - DRAGONETTI, C. - On voidness - Delhi, Motilal Banarsidass, 1995. TORELLA, R. - Il pensiero dell'India - Roma, Carocci, 2008.

WALSER, J. - Nāgārjuna in Context - New York, Columbia University Press, 2005. WOOD, T. - Nāgārjunian disputations - Honolulu, University of Hawaii Press, 1994. WILLIAMS, P. - Il buddhismo dell'India - Roma, Ubaldini, 2002. 